\title{
Self-reported medical history survey of humans as a measure of health risk to the chimpanzees (Pan troglodytes schweinfurthii) of Kibale National Park, Uganda
}

\author{
Hayley Rebecca Adams, Jonathan M. Sleeman, Innocent Rwego and John C. New
}

\begin{abstract}
Kibale National Park (KNP), Uganda, has a number of chimpanzees habituated for tourism. The close genetic relationship between humans and chimpanzees means that there is the potential for disease transmission between the two. The aim of this study was to establish the diseases to which chimpanzees may be exposed by surveying the medical histories of humans in contact with the chimpanzees of KNP. Medical questionnaires were given to tourists visiting $\mathrm{KNP}$ and to the population of a village close to the park. The 62 tourist surveys returned indicated a high prevalence of disease symptoms, in particular diarrhoea, as well as ongoing infectious diseases and a lack of current vaccinations. The 50 local surveys returned also indicated a high prevalence of disease symptoms, in particular respiratory disease, along with a low rate of vaccination and a high frequency of visual contact with the chimpanzees both within and outside KNP. This study
\end{abstract}

indicates that humans are a potential source of infection for chimpanzees. The results, which have been communicated to the appropriate authorities, will assist in the devising of proper tourist viewing regulations and provide local health authorities with the information necessary to improve both public health and chimpanzee health. Further recommendations include education of tourists regarding appropriate vaccinations, hand washing prior to the visit, the use of facemasks during the visit, and the provision of latrines. Chimpanzee ecotourism is becoming increasingly popular and protecting the chimpanzees' health will help to ensure that ecotourism is a sustainable activity.

Keywords Chimpanzees, ecotourism, human diseases, Kibale National Park, Pan troglodytes schweinfurthii, Uganda.

\section{Introduction}

Ecotourism in Uganda has become an economic resource and a viable strategy for sustainable development. There are an estimated 3000-4000 chimpanzees of the eastern subspecies Pan troglodytes schweinfurthii in western Uganda. Kibale National Park (KNP) has approximately 500 chimpanzees (Obua, 1997), some of which are habituated for viewing by tourists. The close genetic relationship between chimpanzees and humans means that there exists the potential for the transmission

Hayley Rebecca Adams (Corresponding author) 2017 Cherokee Bluff Drive, Knoxville, TN 37920, USA. Present address: 1045 South Parkcrest Street, Gilbert, AZ 85296, USA. E-mail: hadams1257@aol.com

Jonathan M. Sleeman Department of Clinical Sciences, College of Veterinary Medicine and Biomedical Sciences, Colorado State University, Fort Collins, CO 80523, USA. Present address: Wildlife Center of Virginia, PO Box 1557, Waynesboro, VA 22980, USA

Innocent Rwego C/o Dr John Bosco Nizeye, Department of Wild Animal Resource Management, Faculty of Veterinary Medicine, Box 7062. Kampala, Uganda

John C. New Department of Comparative Medicine, College of Veterinary Medicine, The University of Tennessee, PO Box 1071, Knoxville, TN 37901-1071, USA

Revised manuscript accepted for publication 24 May 2001 of disease between them (Ott-Joslin, 1993). Potential routes of transmission include aerosol, faecal-oral, water contamination and fomites. Chimpanzees may be vulnerable to human diseases because of a lack of immunity to these pathogens (McCallum \& Dobson, 1995).

Several outbreaks of disease, believed to be of human origin, have been reported among chimpanzee populations. In the late 1960s in Tanzania an epidemic of a polio-like virus was suspected to have spread from a nearby village, and 15 chimpanzees were either severely crippled or died as a result (Goodall, 1971). More recently, a similar outbreak occurred among chimpanzees in the Democratic Republic of Congo (Kortlandt, 1996), and a flu-like epidemic killed at least 11 chimpanzees in Tanzania (Kortlandt, 1996). Outbreaks of scabies, intestinal parasites, yaws (a syphilis-like infection in humans), and a respiratory infection suspected to be measles, have all been reported in great apes, and are suspected to be of human origin (Hastings et al., 1991; Murray et al., 1991; Edroma et al., 1997; Kalema et al., 1998; Mudakikwa et al., 1998; Pusey, 1998).

Human proximity to great apes is often necessary (e.g. researchers, tourists) or unavoidable (local population), and therefore effective measures must be developed to reduce the risk of transmission of disease from humans 
to chimpanzees. Tourists are considered to be more susceptible to infectious diseases due to the stress of travel and exposure to novel pathogens, and may play a role in the spread of diseases to new areas (Wilson, 1995; Ostroff \& Kozarsky, 1998). Some regulations designed to reduce the transmission of disease from humans are enforced in KNP, but little research has been done to establish the exact nature of the chimpanzees' risk of contracting human diseases. The aims of this study were: to establish the potential for transmission of human disease to chimpanzees by surveying the medical histories of visitors to KNP and of those people living in close proximity to the park, to determine the nature of the risk to chimpanzees, and to offer suggestions on risk reduction.

\section{Methods}

Medical histories for selected diseases and conditions were obtained from tourists visiting the Kanyanchu Visitor Centre at KNP $\left(0^{\circ} 13^{\prime}-0^{\circ} 41^{\prime} \mathrm{N}, 30^{\circ} 9^{\prime}-30^{\circ} 32^{\prime} \mathrm{E}\right)$ between July 1998 and November 1999, and from a cross-section of the local population at Bigodi, a village bordering KNP in July 1999. Informed consent was established prior to the survey and confidentiality was maintained. Permission to conduct this research was granted by the Uganda National Council for Science and Technology (UNCST) and the Uganda Wildlife Authority (UWA).

Each participant was given a two-page questionnaire comprising 10 short-answer or 'check all that apply' type questions. Tourists were asked to complete the questionnaire before visiting the chimpanzees. Those surveyed were asked to provide information on vaccination history, disease history, recent disease symptoms, country of origin, length of stay in Africa, as well as in Uganda, and basic demography. The questionnaire for locals was translated into the local language and consisted of questions on medical history, frequency of chimpanzee sightings inside and outside KNP (as a measure of proximity), and frequency of travel through KNP. One of the authors (IR) administered the surveys to the local population around KNP with the assistance of the Kabarole District Chairperson, Mr A.B. Kayonga. Both questionnaires are available upon request from the HRA.

\section{Results}

\section{Surveys of tourists}

Of the 62 tourists surveyed, 68 per cent were from European countries, 15 per cent from Australia, 10 per cent from the USA and 8 per cent from African countries. The average age of those surveyed was 30 (range 18-61). Fifty-five per cent were male and 45 per cent were female. The average time spent in Africa, by non-Africans, was 59 days, and the average time visiting Uganda was 14 days.

Those tourists vaccinated against tuberculosis all had vaccinations that were considered current, but of those vaccinated against measles, polio, influenza, mumps and viral hepatitis $\mathrm{A}$, a number were not considered current (Table 1). The most common symptoms of illness experienced by tourists during the 6 months prior to their arrival in Africa or during their stay in Africa were diarrhoea (55 per cent), coughing (24 per cent), fever (15 per cent) and vomiting (13 per cent) (Fig. 1). There was an increase in all the clinical signs listed on the survey among tourists during their visit to Africa compared with the previous 6 months in their country of origin.

Of those individuals previously diagnosed with herpesvirus, hepatitis A, poliovirus, influenza, chicken pox, measles or mumps, five cases of herpes, six of influenza, and one of chicken pox were considered infectious at the time of the visit (using periods of infectivity indicated by Isselbacher et al., 1994). In addition, 30 people (48 per cent) had been previously tested for tuberculosis, 26 (42 per cent) had never been tested, four ( 6 per cent) were unsure whether they had been tested and two did not respond to this question. Of those who had been tested, three (10 per cent) had positive test results (by intradermal skin testing methods) that could indicate that they were infectious at the time of their visit.

Twenty-three ( 37 per cent) of the tourists had visited another group of habituated chimpanzees or gorillas prior to their visit to $\mathrm{KNP}$, and after leaving Kibale 30 per cent planned to visit other groups of apes. Prior to the visit 43 (69 per cent) of the tourists had been informed of the viewing regulations for KNP.

Table 1 Vaccination history taken in July 1998-November 1999 from 62 tourists to Kibale National Park, Uganda, and 50 local people from Bigodi, a village that borders the park. Per cent of tourists considered current for vaccinations were as recommended by Isselbacher et al. (1994); this information could not be determined for the local populace as memory recall of vaccination dates was poor, illustrating the need for written vaccination records.

\begin{tabular}{lll}
\hline & $\begin{array}{l}\text { Tourists vaccinated } \\
\text { (vaccinations current) } \\
\text { (per cent) }\end{array}$ & $\begin{array}{l}\text { Locals } \\
\text { vaccinated } \\
\text { (per cent) }\end{array}$ \\
\hline Measles & $45(37)$ & 70 \\
Polio & $87(69)$ & 60 \\
Influenza & $6(3)$ & 50 \\
Tuberculosis & $55(55)$ & 30 \\
Tetanus & Not asked & 12 \\
Mumps & $32(21)$ & 8 \\
Viral hepatitis A & $89(58)$ & 2 \\
\hline
\end{tabular}




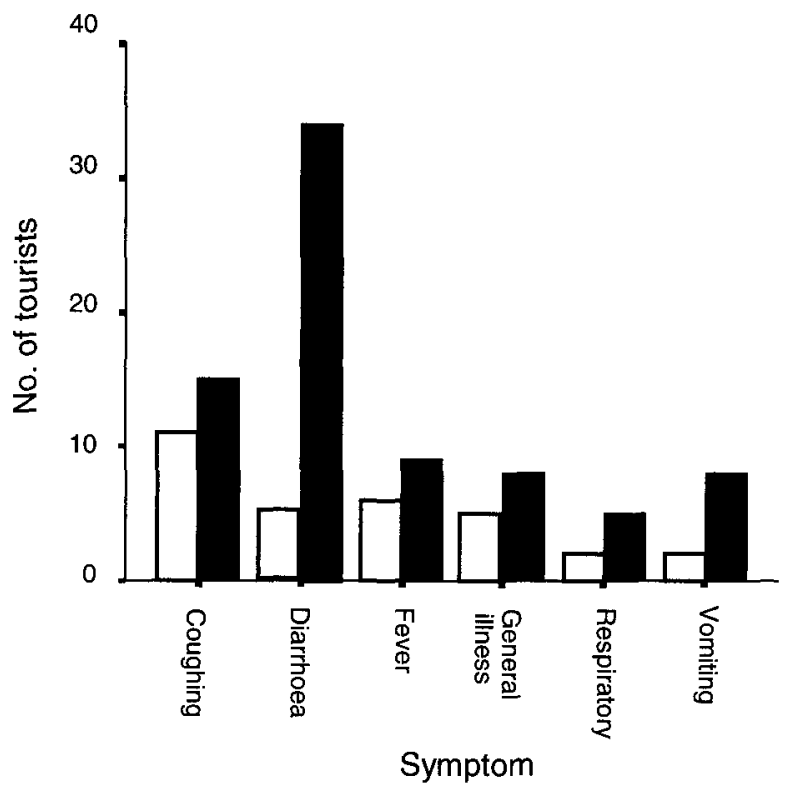

Fig. 1 Symptoms of illness experienced by tourists during the 6 months prior to their visit to Kibale National Park, Uganda. Symptoms are divided according to whether they occurred in the tourists' country of origin (white bars) or during their time in Africa (shaded bars).

\section{Surveys of the local human population}

Of the 50 local people surveyed, 36 were subsistence farmers, nine were staff of KNP, two were students and three were shopkeepers (mean age 34, range 18-79). Thirty were male (60 per cent) and 20 were female (40 per cent).

Overall the vaccination rates of the local population were low (Table 1). Within the 6 months prior to being surveyed, fever (82 per cent) and coughing (64 per cent) were the most frequently reported symptoms of illness (Table 2). The most common previously diagnosed diseases (i.e. subjects were no longer considered to be infected) were malaria, measles, intestinal parasites, typhoid and yellow fever. Diseases that were considered to be currently infectious (using periods of infectivity given in Isselbacher et al., 1994) included malaria, intestinal parasites, skin disorders and typhoid (Table 3 ).

Of the 14 people who answered the question regarding testing for tuberculosis, four (28 per cent) answered yes to having been tested (of which three were positive), five ( 36 per cent) answered no, and five ( 36 per cent) did not know whether or not they had been tested.

Twenty-five ( 50 per cent) of the 50 locals who were surveyed reported that they had entered KNP during the last year, with the following frequencies: 5 rarely (20 per cent); 3 occasionally (12 per cent); and 17 frequently ( 68 per cent). All had seen chimpanzees in the forest during their visits, and the relative frequency
Table 2 Symptoms of illness experienced within the last 6 months by 50 persons from the population of Bigodi, a village bordering Kibale National Park, Uganda. Surveys were administered in July 1999.

\begin{tabular}{ll}
\hline & Percentage of people showing symptom \\
\hline Fever & 82 \\
Coughing & 64 \\
Respiratory distress & 26 \\
Diarrhoea & 24 \\
Vomiting & 24 \\
General illness & 22 \\
\hline
\end{tabular}

Table 3 Diagnosis of specific diseases among 50 persons surveyed in Bigodi, a village that borders Kibale National Park, Uganda. Surveys were administered in July 1999.

\begin{tabular}{llc}
\hline Disease & $\begin{array}{l}\text { Previously } \\
\text { infected (per cent) }\end{array}$ & $\begin{array}{l}\text { Currently } \\
\text { infected (per cent) }\end{array}$ \\
\hline Malaria & 64 & 20 \\
Measles & 48 & 0 \\
Intestinal parasites & 38 & 12 \\
Typhoid & 32 & 4 \\
Yellow fever & 30 & 0 \\
Paratyphoid & 28 & 0 \\
Mumps & 26 & 0 \\
Cholera & 24 & 0 \\
Chicken pox & 22 & 0 \\
Skin disorders & 10 & 10 \\
Poliovirus & 8 & 0 \\
Hepatitis A & 2 & 0 \\
Herpes simplex & 0 & 0 \\
\hline
\end{tabular}

of sighting was: 2 rarely ( 8 per cent); 2 occasionally ( 8 per cent); and 21 frequently ( 84 per cent). A total of 11 people (44 per cent) reported that they had defecated while in the forest, of which only four (36 per cent) buried their waste.

Thirty-five of the 50 people (70 per cent) reported sightings of chimpanzees outside KNP as follows: 7 rarely (20 per cent); 14 occasionally (40 per cent); and 14 frequently ( 40 per cent). While outside the park boundaries, chimpanzees were observed raiding crops by 18 of the locals surveyed ( 51 per cent), and otherwise 20 of the locals surveyed (57 per cent) reported seeing chimpanzees on the move.

\section{Discussion}

This study is limited to self-reported medical histories. We did not attempt to estimate current human disease rates, current disease frequency at KNP, the proximity of humans to chimpanzees during visits in KNP, or the extent to which tourists followed the rules of KNP. However, this study does indicate that humans living in proximity to and/or visiting KNP are potential sources 
of infection for chimpanzees. The increasing development of tourism, the long-term presence of researchers and field staff, and local human activity in the proximity of the park boundaries are likely to further increase the potential for the transmission of disease to the chimpanzees.

It is apparent that many of the visitors to the park have not been vaccinated or are not currently vaccinated against diseases that could potentially infect the chimpanzees. Encouragement of vaccination of tourists is appropriate and might be accomplished through the distribution (via park authorities, to tourist agencies and embassies) of information on the potential for disease transmission and a recommended list of vaccinations for visitors to KNP. The Uganda Wildlife Authority could also consider mandatory vaccination requirements, based on studies of which diseases chimpanzees can potentially contract from humans.

A high proportion of tourists reported clinical signs of an infectious disease, especially diarrhoea. Coughing and diarrhoea may increase transmission of an agent by increasing the frequency and/or force of its dispersal into the environment (Isselbacher et al., 1994). Of the three tourists that had tested positive for tuberculosis, none had received treatment after the test. However, prior vaccination for tuberculosis using tuberculin purified protein derivative may induce a positive reaction when testing by intradermal methods (Daniel, 1994).

Approximately 2000 people visited KNP during the study period (UWA, unpublished data). To provide 99 per cent confidence of detecting diseases with at least a 10 per cent prevalence a minimum sample of 44 individuals in every 10,000 is required (Martin et al., 1987). Our sample size of 62 surveys is therefore adequate for the purposes of this study, although misdiagnoses, misunderstanding of the questionnaire, a lack of knowledge on the part of the subjects of their own medical histories, and the fact that some individuals left sections of the survey unanswered could have potentially influenced the results.

Knowledge of common diseases carried by tourists will assist the UWA in developing appropriate tourist regulations to prevent disease transmission (results from this study were presented to the park authorities, UNCST and UWA in July 2000). For example, it was recommended by the International Gorilla Conservation Programme that the minimum distance of $5 \mathrm{~m}$ maintained between gorillas groups and tourists be expanded to $7 \mathrm{~m}$ (Anonymous, 1999). This increase should also be considered for chimpanzee tourism. Based on our findings, regulations could sensibly be extended to include the use of facemasks to reduce or prevent the transmission of airborne disease agents and the enforce- ment of the right to refuse a visitor if he or she is ill. Other measures might include the mandatory washing of hands and the use of disinfectant foot baths for all tourists prior to their visit, and construction of adequate pit latrines to ensure proper disposal of human waste. When in the forest, or away from such facilities, humans should be required to bury their waste or remove it. Regular examination and vaccination of park staff and field researchers would minimize the risk of disease transmission from those in frequent contact with the chimpanzees.

The local population appear to have a high prevalence of certain infectious diseases and a high frequency of clinical signs. Diarrhoea was the most common clinical sign among tourists, whereas respiratory signs were most common among the local population. Thus different control measures may be necessary for the two groups. The local human population, who appear to have a low vaccination rate, report a high frequency of visual contact with the chimpanzees both within and outside KNP, and as such the potential for disease transmission should be included in the health management plan of the chimpanzees.

The estimated local human population living in proximity to KNP is 35,000 (Anonymous, 1997). Contact between the local people and the chimpanzees and/or their forest habitat is less regulated than that of the tourists and so it will be more difficult to prevent the transmission of disease from local people. This study provides a wildlife-related argument for proper local vaccination campaigns. Another important measure that could lower disease transmission is the improvement of community sanitation, through the provision of adequate pit latrines in the villages close to the forest and in forest areas that have a high level of human activity.

Further investigation into the risk of transmission of disease from humans to chimpanzees could include serological surveys of tourists and local people for common infectious diseases, faecal examination for parasites, faecal cultures for pathogenic bacteria, throat culture swabs, and intradermal skin testing for tuberculosis. Development of non-invasive monitoring of chimpanzee health status, via opportunistic blood, skin, urine or faecal sampling, and necropsies, would help to document any disease transmission that is occurring between humans and the chimpanzee population of KNP.

\section{Acknowledgements}

We thank the Uganda Wildlife Authority, particularly Mr Samson Werikhe (1998) and Ms Apophia Atukunda (1999), Directors of Scientific Research; as well as Mr Julius Ecuru of the Uganda National Council for 
Science and Technology, for the permission to conduct this study. Valuable assistance was provided by the Kabarole District Chairperson, Mr A.B. Kayonga; Chief Wardens of Kibale National Park, Mr Keith Musana (1998), and Mr Michael Edegu (1999); the warden of Tourism at KNP, Mr Aggrey Rwetsiba; the UWA Veterinary Officer, Dr Gladys Kalema; and Debby Cox of the Jane Goodall Institute. Special thanks to Mr John Bandashi, and to Julia Lloyd and Daniela Pezzato of The Kibale Primate Habituation Project for assistance with the administration of the surveys, and to Dr Antoine Mudakikwa and Dr Juergen Schumacher for translation of the questionnaire and consent form. This project was funded by the Center for Conservation Medicine, Tufts University and a Geraldine R. Dodge Foundation's Frontiers for Veterinary Medicine grant.

\section{References}

Anonymous (1997) Statistical Abstract. Ministry of Planning and Economic Development, Republic of Uganda.

Anonymous (1999) Preliminary recommendations on gorilla tourism rules presented at the International Gorilla Conservation Programme Regional Meeting. In Gorilla Tourism and Human Diseases. Unpublished Report, Rwanda.

Daniel, T. (1994) Tuberculosis. In Harrisons's Volume 1; Principles of Internal Medicine, 13th edn (eds K. J. Isselbacher,

E. Braunwald, J. D. Wilson, J. B. Martin, A. S. Fauci and

D. L. Kasper), pp. 710-718. McGraw-Hill, New York

Edroma, E., Rosen, N. \& Miller, P. (eds) (1997) Conserving the Chimpanzees of Uganda: Population and Habitat Viability Assessment for Pan troglodytes schweinfurthii. IUCN/SSC Conservation Breeding Specialist Group, Apple Valley, MN.

Goodall, J. (1971) In the Shadow of Man. Houghton Mifflin, Boston, MA.

Hastings, B.E., Kenny, D., Lowenstine, L.J. \& Foster, J.W. (1991) Mountain gorillas and measles: ontogeny of a wildlife vaccination program. In Proceedings of the American Association of Zoo Veterinarians Annual Meeting (ed. R. E. Junge), pp. 198-205. AAZU, Philadelphia, PA.

Isselbacher, K.J., Braunwald, E., Wilson, J.D., Martin, J.B., Fauci, A.S. \& Kasper, D.L. (eds) (1994) Harrison's Volumes 1 \& 2; Principles of Internal Medicine, 13th edn. McGraw-Hill, New York.

Kalema, G., Kock, R. \& Macfie, E. (1998) An outbreak of sarcoptic mange in free-ranging mountain gorillas (Gorilla gorilla beringei) in Bwindi Impenetrable National Park, South Western Ugnada. In Proceedings of the American Association of Zoo Veterinarians/American Association of Wildlife Veterinarians Joint Conference (ed. C. K. Baer), p. 438. AAZU, Philadelphia, USA.

Kortlandt, A. (1996) An epidemic of limb paresis (polio?) among the chimpanzee population at Beni (Zaire) in 1964, possibly transmitted by humans. Pan Africa News, 3, 9.

Martin, S.W., Meek, A.H. \& Willberge, P. (1987) Veterinary Epidemiology, Principles and Methods. Iowa State University Press, Ames, USA.
McCallum, H. \& Dobson, A. (1995) Detecting disease and parasite threats to endangered species and ecosystems. Trends in Ecology and Evolution, 6, 190-194.

Mudakikwa, A.B., Sleeman, J., Foster, J., Meader, L. \& Patton, S. (1998) An indicator of human impact: gastrointestinal parasites of mountain gorillas (Gorilla gorilla beringei) from the Virunga Volcanoes Region, Central Africa. In Proceedings of the American Association of Zoo Veterinarians/American Association of Wildlife Veterinarians Joint Conference (ed. C. K. Baer), pp. 436-437. AAZU, Philadelphia, USA.

Murray, S., Stem, C. \& Goodall, J. (1991) Intestinal parasites of baboons and chimpanzees in Gombe National Park. In Proceedings of the American Association of Zoo Veterinarians Annual Meeting (ed. R. E. Junge), pp. 244-245. AAZU, Philadelphia, USA.

Obua, J. (1997) The potential, development and ecological impact of ecotourism in Kibale National Park, Uganda. Journal of Environmental Management, 50, 27-38.

Ostroff, S.M. \& Kozarsky, P. (1998) Emerging infectious diseases and travel medicine. Infectious Disease Clinics of North America, 12, 231-241.

Ott-Joslin, J.E. (1993) Zoonotic diseases of nonhuman primates. In Zoo and Wild Animal Medicine Current Therapy 3 (ed. M. F. Fowler), pp. 358-373. W.B. Saunders Company, Philadelphia, USA.

Pusey, A. (1998) Scabies in Chimpanzees of Gombe National Park, Tanzania. European Association of Zoo and Wildlife Veterinarians Newsletter, 1, 10.

Wilson, M.E. (1995) Travel and the emergence of infectious diseases. Emerging Infectious Diseases, 1, 39-46.

\section{Biographical sketches}

Hayley Adams works at Mesa Veterinary Hospital, Phoenix, Arizona. She has a BSc in Zoology and Anthropology from the University of Tennessee and a Doctorate of Veterinary Medicine from the University of Tennessee College of Veterinary Medicine. She has participated in several wildlife research studies in Africa, the United States and Central America.

Dr Jonathan Sleeman is the Director of Veterinary Services at the Wildlife Center of Virginia. He has a Bachelor of Veterinary Medicine from Cambridge University. Following a residency in zoological medicine at the University of Tennessee he was the Field Director of the Mountain Gorilla Veterinary Centre in Rwanda during 1995-1997.

Dr Innocent Rwego is a graduate of the Faculty of Veterinary Medicine, Makerere University, and works with the Mountain Gorilla Veterinary Project. He has studied the health of free-living great apes in Uganda.

John New is Professor in the Department of Comparative Medicine, College of Veterinary Medicine, University of Tennessee. His research interests include the epidemiology of zoonoses and wildlife diseases. 